\title{
Alpine Climate Changes as Reconstructed from Speleothems
}

Silvia Frisia 1 and IAN FaIRChILd 2

1 Museo Tridentino di Scienze Naturali,Via Calepina 14, 38100 Trento, ITALY, frisia@mtsn.tn.it

2 School of Earth Sciences and Geography, Keele University, Staffs, UK, i.j.fairchild@keele.ac.uk

The use of $\delta^{18} \mathrm{O}$ signals from calcite is a major component of speleothem based climate reconstructions. However, the validity of these reconstructions depends on knowledge of the source water isotopic composition. The complex controls on source water composition in the modern climate were investigated during a four-year programme of monthly monitoring of meteoric water $\delta^{18} O_{p}$ along an E-W traverse in Trentino, South-Central Alps at stations from 180 to 2,200 meters above sea level. The monitoring indicates that the modern precipitation $\delta 180_{p}$ signal is influenced by 1) the $\delta^{18} \mathrm{O}_{\mathrm{p}}$ of the air masses from western and southern provenance, 2) the deviation of water vapor transport trajectories due to mountain ranges, and 3) the elevation effect, whereby moisture content in westerly air-masses, which cross $3,000 \mathrm{~m}$ mountain ranges, is more depleted than that in southerly air masses. For example, at the meteorological station set in the Brenta Dolomites (W-Trentino), mean annual $\delta^{18} \mathrm{O}_{\mathrm{p}}$ increases by as much as $1.5 \%$ when southern trajectories dominate over western trajectories.

Because past $\delta^{18} \mathrm{O}_{\mathrm{p}}$ may have varied considerably as a consequence of circulation changes, it is not possible to construct a simple transfer-function for the Holocene, relating the oxygen isotopic composition of speleothem calcite $\left(\delta^{18} O_{c}\right)$ to mean air temperature. It is, therefore, difficult to reconstruct Holocene temperature and rainfall history in the Alps from oxygen isotope profiles of speleothem calcite alone. Current research on Holocene climate change in the Southern Alps focuses on analysis of multiple, independent, annual-resolution proxies within a given speleothem and their relationships to climate parameters. In addition, several stalagmites are generally sampled from different nearby caves.

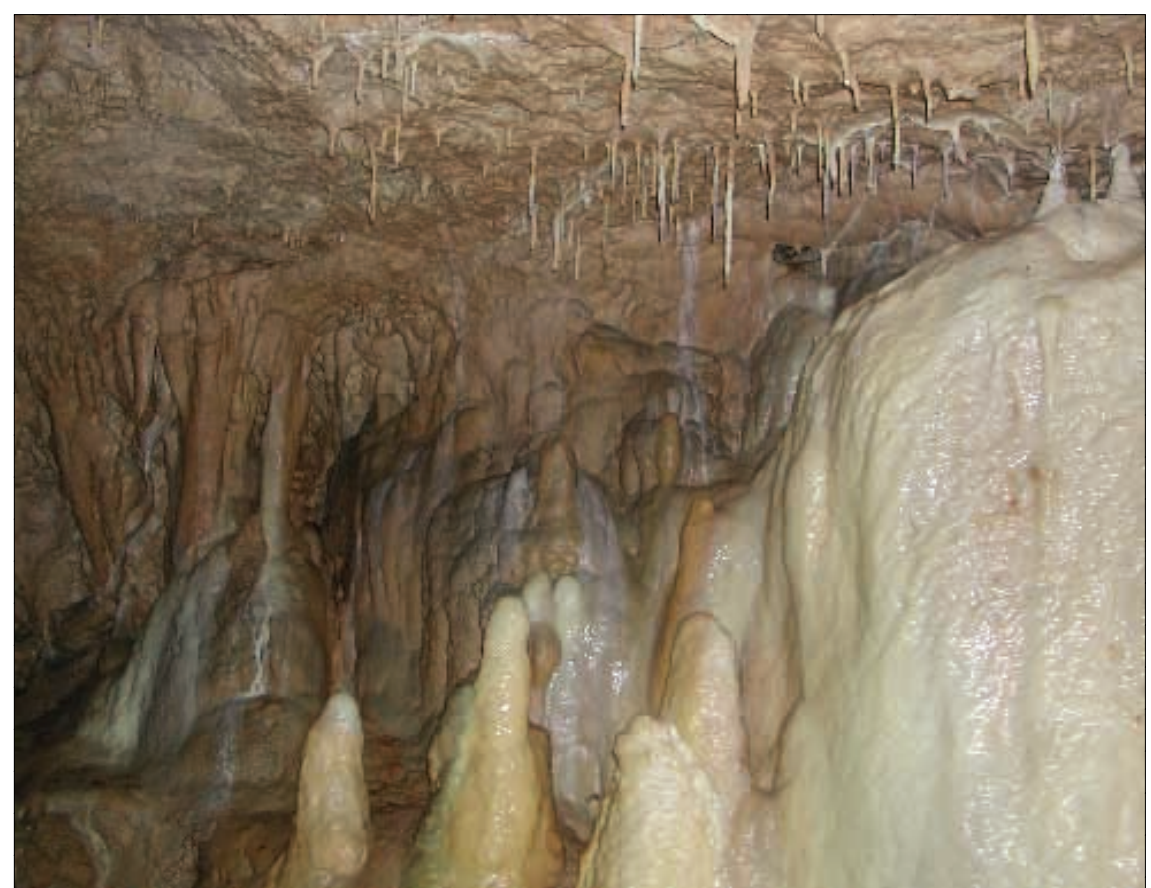

Fig. 1: Grotta di Ernesto (Trentino, Northern Italy). Active stalagmites, which are being monitored for modern seasonal crystal growth and dripwater parameter analyses, and sampled for paleoreconstructions.

For example, at Grotta di Ernesto, at 1,160 meters above sea level (Fig. 1), paleoclimate research has been carried out for the past 6 years. High-resolution, alpine climate and environmental reconstruction from stalagmites has been obtained through the comparison of a $\delta^{18} \mathrm{O}_{\mathrm{c}}, \delta^{13} \mathrm{C}_{\mathrm{c}}, \mathrm{Mg} / \mathrm{Ca}$ ratio and calcite fabric series dated by TIMS U/Th (Fig. 2). Each of these proxy indicators has either a different sensitivity to the same environmental process or records processes which are not registered by the other proxies. In particular, calcite fabrics in shallow subsurface caves such as Grotta di Ernesto are very sensitive to climate-related fluctuations in water availability, seasonal flow changes, and the presence of growth-poisoning particles (or dissolved ions) in dripwater. Comparison of the four proxy data series, combined with the information from the monitoring of modern day precipitation, allows an interpretation of major trends in the Holocene $\delta^{18} \mathrm{O}_{\mathrm{c}}$ profile in terms of regional circulation changes. Figure 2 shows Holocene profiles of four climate proxy indicators loxygen and carbon stable isotopes, $\mathrm{Mg} / \mathrm{Ca}$ ratio and fabrics) for stalagmite $E R$ of Italy.

\section{Mid Holocene Climate}

The most humid period in these records occurred around 7,600 yr BP. This period is indicated by low $\mathrm{Mg} / \mathrm{Ca}$ ratio and low $\delta^{18} \mathrm{O}_{\mathrm{c}}$ values. $\delta^{13} C_{C}$ is also low at this time, suggesting that moisture availability led to increased soil $\mathrm{CO}_{2}$ production. During this humid period from 8,000 to $7,000 \mathrm{yr} B P$, high mountain human settlement sites were abandoned, and agriculture was introduced in the valleys of Trentino.

The 6,700 to 6,570 yr BP interval was probably a relatively warm period. During this time, mean annual $\delta^{18} \mathrm{O}_{\mathrm{w}}$ of precipitation was less depleted (only by about $-0.5 \%$ ) with respect to the present values than is the case for most of the early to mid Holocene, and stalagmite $\delta^{18} \mathrm{O}_{\mathrm{c}}$ was only -0.2 to $-0.4 \%$ o depleted relative to the present value. This period is also marked by gla76 from the Southern-Central Alps 


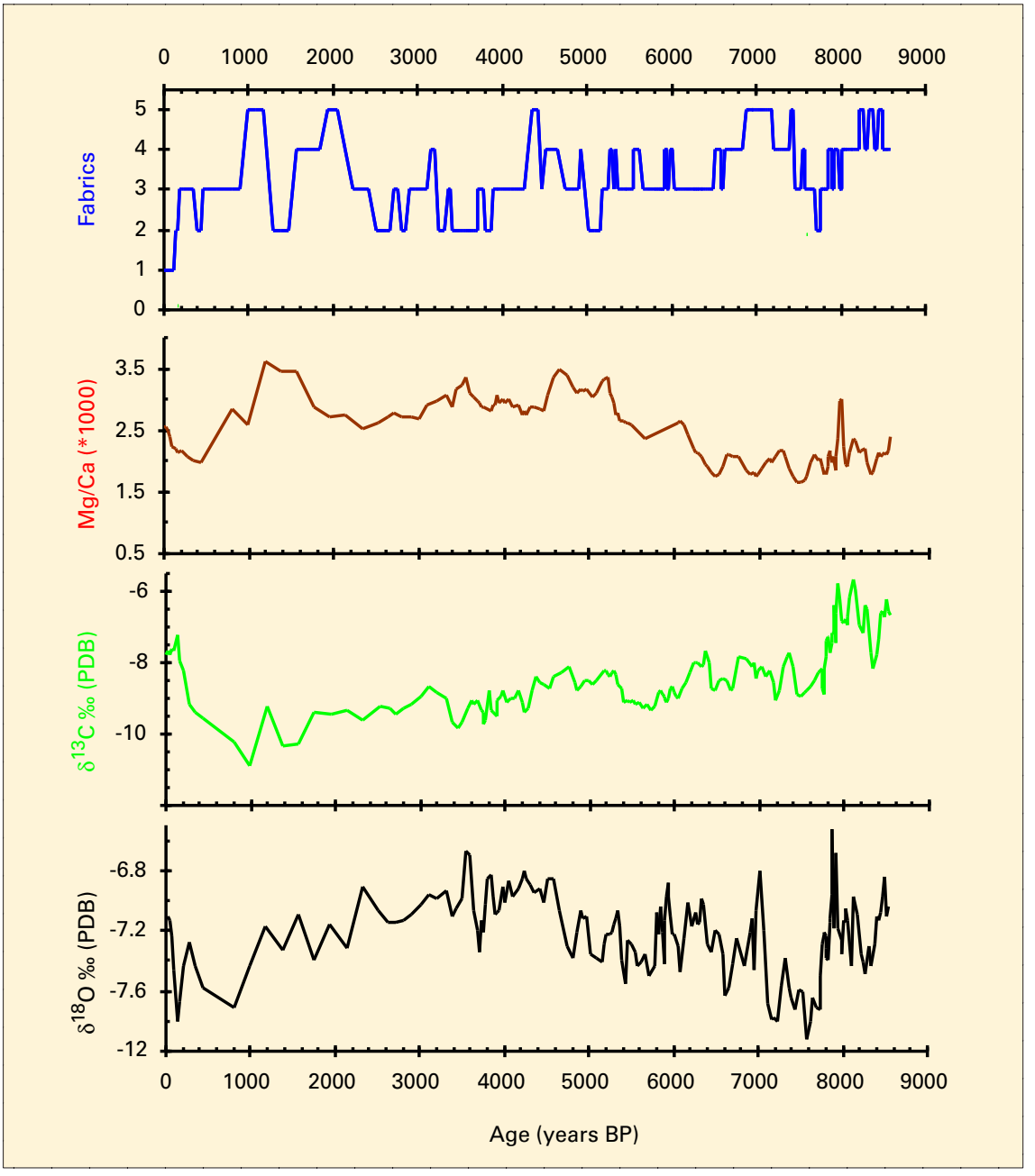

Fig. 2: Holocene profiles of four climate proxy indicators loxygen and carbon stable isotopes, Mg/Ca ratio and fabrics) for stalagmite ER 76 from the Southern-Central Alps of Italy. Fabric numbers correspond to: 1) columnar; 2) columnar to microcrystalline, 3) microcrystalline, 4) microcrystalline to dendritic and 5) dendritic (see Frisia et al., 2000 for details).

cial retreat in the Central Swiss Alps (Hormes et al., 2001).

All of the speleothem proxies record a change in the moisture balance in the Southern Alps starting at 5,400 $\mathrm{yr}$ BP. This change affected vegetation $\left(\delta^{13} C_{c}\right)$, the residence time of the water in the aquifer (Mg/Ca ratio), seasonal variability in physico-chemical parameters (fabrics) and precipitation isotopic composition $\left(\delta^{18} O_{c}\right)$. The change probably involved a change in air mass trajectories causing additional 180-enriched moisture to be advected into the Southern Alps. If the analogy with today's air circulation patterns holds true, it is possible that southern trajectories were predominant over western trajectories from around 5,200 to 2,400 yr $\mathrm{BP}$. This long and relatively dry period corresponds to prolonged glacier minima in the Central Swiss
Alps (Hormes et al., 2001), and had important societal implications. Archaeological data indicate that the practice of high alpine pasturage began around 5,500-5,200 yr BP. There is also archaeological evidence that man and cattle crossed high alpine passes during this period. It is interesting to note that a major mid-Holocene event recorded by many paleodata, the 4,200 yr BP dry spell, is not recorded in the speleothem $\delta^{18} \mathrm{O}_{\mathrm{c}}$ profile, though it is recorded by a change to dendritic fabric between 4,400 and 4,200 yr BP.This fabric type is believed to develop under limited dripwater availability (Frisia et al. 2000).

\section{Late Holocene Climate}

The interpretation of the past 3800 years has to account for the strong anthropogenic modification of vegetation and, consequently, soil $\left(\delta^{13} C_{c}\right)$ as a result of enormous quantities of wood used in smelting activities in the Southern Alps. The decrease in stalagmite growth rates at Grotta di Ernesto at this time (McDermott et al. 1999) may be a consequence of human impact, rather than climate change. Subsequent to $3,800 \mathrm{yr} \mathrm{BP}$, the $\delta^{18} \mathrm{O}_{\mathrm{C}}$ profile tends toward values similar, or more depleted than, present-day values. The $\mathrm{Mg} / \mathrm{Ca}$ ratio curve, on the other hand, remains characterized by values higher than at present-day, indicating that the climate mode established around 5,200 yr BP persisted until around 2,400 yr BP. The dominant calcite fabric at this time is indicative of seasonal variability in dripwater flow and impurity content. However, because the stacking of crystallites is regular, there was less contrast between winter-spring and summer-autumn deposition (Frisia et al., 2000).

Holocene climate variability in the Alps had a profound impact on the environment and society. We believe that alpine speleothems paleodata provide a powerful tool for reconstructing this variability accurately and at high resolution. However interpretation of speleothem archives requires cross-correlation between multiple independent proxies. The interpretations described here will be improved by higher resolution studies and improved calibrations from modern process studies and climate parameters.

\section{Acknowledgement:}

Helpful comments from Christoph Spötl have been greatly appreciated.

\section{REFERENCES}

Frisia, S., Borsato, A., Fairchild, I.J., \& McDermott,

F., (2000), Calcite fabrics, growth mechanisms, and environments of formation in speleothems from the Italian Alps and southwestern Ireland. Journal Sedimentary Research, 70, 1183-1196.

Hormes, A. Müller B. U Schluchter, C. 2001, The Alps with little ice: evidence for eight Holocene phases of reduced glacier extent in the Central Swiss Alps. The Holocene, 11, 255-265.

McDermott F., Frisia S., Huang Y., Longinelli A., Spiro B. Heaton T.H.E., Hawkesworth C., Borsato A Keppens E., Fairchild I.J., Van der Borg K., Verheyden S., Selmo E., 1999, Holocene Climate variability in Europe: Evidence from $\delta^{18} 0$ and textural variations in speleothems, Quaternary Science Reviews, Vol 18, p. 1021-1038. 